
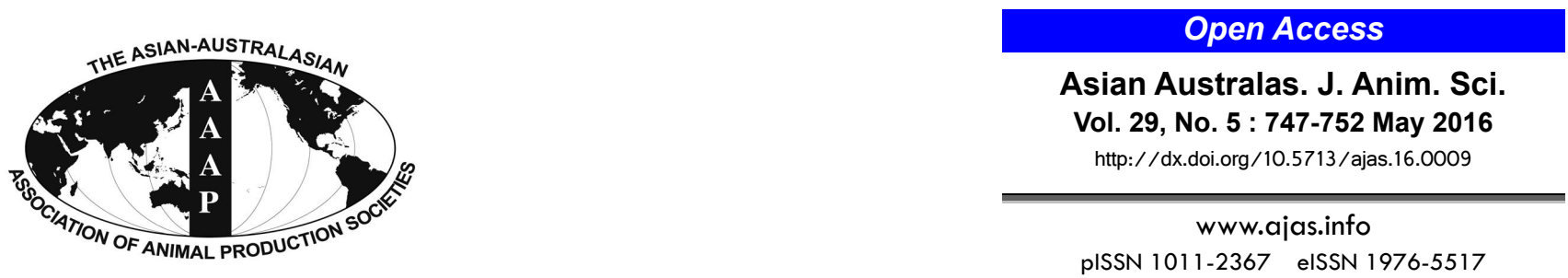

\title{
Changes in Salivary Cortisol Concentration in Horses during Different Types of Exercise
}

\author{
Ok-Deuk Kang and Wang-Shik Lee ${ }^{1, *}$ \\ Department of Hippotherapy Welfare, SungDuk C.University, Yeongcheon 38801, Korea
}

\begin{abstract}
This study aimed to estimate the change of stress level in horses based on cortisol concentration levels in their saliva. A total of 61 horses were divided into the following three groups: i) tourist riding experience (TR, $n=23)$; ii) resting group (RR, $n=14)$; and iii) horse-riding education ( $E R, n=24)$. The saliva samples of TR and ER groups were taken using plain cotton Salivettes four times a day: at 07:00 (basal), 11:00 (Exercise 1, after 1-hour exercise in the morning), 14:00 (Exercise 2, after 1-hour exercise in the afternoon), and 16:00 (Exercise 3, after 1-hour exercise in the afternoon). The saliva samples of RR were measured at the same time. The samples were analyzed using the SAS program general linear model procedure. In a percentage relative to the base value, cortisol levels in Exercise 3 were confirmed to decrease in all groups as compared to the basal value percentage in the following sequence: $\mathrm{ER}>\mathrm{TR}>\mathrm{RR}$. The highest peak was confirmed in Exercise 2 (approximately 131\%) of RR group and the lowest peak appeared in Exercise 3 (approximately 52\%) of ER group. Therefore, resting without any particular exercise can also increase the stress level of horses. Thus, it is better to exercise, as exercise can reduce the stress level, even in cases when riders are clumsy or lack appropriate horse-riding experience. The results of the present study are useful to equestrian center owners and educational riding instructors in that they provide a meaningful insight into a better horse management. (Key Words: Animal Welfare, Horse, Riding Experience, Stress, Salivary Cortisol)
\end{abstract}

\section{INTRODUCTION}

There are several methods to assess stress levels in horses caused by exercise, including heart rate, lactate density, and cortisol (Marc et al., 2000). Among these, cortisol is frequently used to assess stress levels induced by exercise (Wellhoener et al., 2004; Malinowski et al., 2006; Ferlazzo et al., 2009). Cortisol hormone produced by the adrenal cortex is one of the main chemical substances indicating the level of stress (Strzelec et al., 2011). For example, Wellhoener et al. (2004) reported that cortisol concentration levels in the human body doubled during an hour of exercise, while Linden et al. (1991) demonstrated that cortisol concentration levels in horses increased after show jumping, cross country, and trotting race.

\footnotetext{
* Corresponding Author: Wang-Shik Lee. Tel: +82-64-754-3333, Fax: +82-64-725-2403, E-mail: leewshik@naver.com

${ }^{1}$ Division of Biotechnology, Jeju National University, Jeju 690756, Korea.

Submitted Jan. 5, 2016; Revised Feb. 16, 2016; Accepted Feb. 29, 2016
}

The methods to measure the level of cortisol concentration include the measurement of the hormone concentration through blood serum, saliva, or urine and the measurement of the amount of neurotransmitter (Mostl and Palme, 2002). For ethical considerations, many previous studies on stress have been conducted through the measurement of cortisol concentration in blood and saliva (Shanahan, 2003; Harewood and McGowan, 2005; Strzelec et al., 2011; Larsson et al., 2013; Peeters et al., 2013). For animals, any method using blood serum can cause additional stress during blood collection (Strzeled et al., 2011). Thus, in order to reduce stress, the measurement of cortisol concentration has been widely conducted through the convenient noninvasive saliva method (Van der Kolk et al., 2001; Peters et al., 2011; Strzelec et al., 2011; Kędzierski et al., 2013).

Since Jeju crossbred horses are small in size, they can be safely used by beginners and are most frequently used in horse-riding experience services for tourists and horseriding instruction programs. In horse riding, rider 
techniques in using reins and aids are crucial in terms of communicating with the horse (Kang et al., 2010). Therefore, it is expected that horse riding as performed by a person with a poor technique can cause stress in the horse. Said differently, a horse can be stressed by excessive pulling of reins, improper use of aids, and unstable riding posture.

Many previous studies have been conducted on stress in horses, such as trailer loading stress in horses (Shanahan, 2003), horses participating in a dressage competition (Moons et al., 2002; Harewood and McGowan, 2005), horses for endurance competition (Larsson et al., 2013), and horses for jumping (Linden et al., 1991; Vincze et al., 2010; Peeters et al., 2013). In these and other relevant studies, cortisol concentrations were measured and verified using the Enzyme Immuno-Assay (EIA) Kit (Moons et al., 2002; Shanahan, 2003; Strzelec et al., 2011; 2013). Therefore, the present study aimed to estimate the change of stress levels in horses during different types of exercise by analyzing the cortisol concentration in saliva using the EIA Kit (Salimetrics, Webster, TX, USA).

\section{MATERIALS AND METHODS}

\section{Experimental animals and physical exercises}

All procedures in the present study were performed in accordance with the IACUC (Institutional Animal Care and Use Committee) of Jeju National University, South Korea. A total of 61 clinically healthy Jeju crossbred horses (28 gelding and 33 mare horses) were divided into the following three groups: i) ten geldings and thirteen mares aged from 5 to 20 years old for tourist riding (TR group, horse-riding experience for tourists; $12.61 \pm 5.55$ years; $n=$ $23)$; ii) five geldings and nine mares aged from 5 to 22 years old for resting ( $R R$ group, in the paddock without special exercise; $9.93 \pm 4.38$ years; $n=14$ ); and iii) thirteen geldings and eleven mares aged from 4 to 20 years old for education horse-riding (ER group, for people learning horse riding, such as walk and trot; $9.88 \pm 5.92$ years; $n=24$ ). Furthermore, the horses were divided in four groups according to their age: A1 (1 to 5 years old, $n=14)$, A2 (6 to 10 years old, $n=16$ ), A3 (11 to 15 years old, $n=15$ ), and A4 (16 to 20 years old, $n=16$ ). Finally, the horses were divided in two groups according to their gender: geldings (n $=28)$ and mares $(n=33)$.

All horses in three groups were managed in the same place and had been used as riding horses for over two years before the study. However, their work was different. The horses in TR group had been used for tourist riding experience; ER group had been used for horse-riding education; RR group was randomly selected among the horses that had performed both types of exercise. The horses usually worked from 9:00 am to 5:00 pm. At the end of the day, they spent the night in the pastures to restart their work in the morning.

This study was based on the method of using saliva to measure cortisol concentration in horses; this method was previously verified by other researchers (Van der Kolk et al., 2001; Peters et al., 2011). The horses in TR group went around a $1 \mathrm{~km}$ course at normal or fast speed. Then they repeated the process with a rider on their back, taking a round of the given course and coming back to the starting point and again allowing another rider on their back. The total 3-hour ride was held both in the morning (1 hour, between 10 to $11 \mathrm{am}$ ) and in the afternoon (each hour; between 13 to $14 \mathrm{pm}$ and 14 to $15 \mathrm{pm}$ ). The horses in RR group took a rest without any particular exercise and were tied by a rope (approximately $1.2 \mathrm{~m}$ long). They had to wait for tourists while being tied by a rope at least during their standard working time. Thus, the horses in RR group were fastened by a rope for three hours in total. ER group participated in 3-hour riding lessons in the morning ( 1 hour, between 10 to $11 \mathrm{am}$ ) and in the afternoon (each hour; between 13 to $14 \mathrm{pm}$ and 14 to $15 \mathrm{pm}$ ). A total of 14 horses and 4 instructors were simultaneously involved in the course of ER group. The horses of TR and ER groups had a free time at the paddock except for the exercise time.

\section{Sampling and measurements}

All saliva samples for basal values were taken four times a day: at 07:00 (basal) in the paddock of $25 \times 35 \mathrm{~m}$, 11:00 (Exercise 1), 14:00 (Exercise 2), and 16:00 (Exercise 3). Saliva samples of TR and ER groups were collected in the paddock and those of RR group were collected while the horses were tied up in a line outdoors (except for the basal values).

Saliva samples were collected using Salivette tubes (Sarstedt) with cotton wool (Sarstedt, Numbrecht, Germany). The cotton was inserted and rubbed into the horse's mouth and then placed onto the tongue of the horse using metal tweezers. All saliva samples were frozen at $-20^{\circ} \mathrm{C}$ for 2 hours immediately after collection.

The kit for measuring the concentration of cortisol in the saliva samples was assayed by Salimetrics Salivary Cortisol Enzyme Immuno-Assay Kit (Diagnostic System Laboratories Inc., Webster, TX, USA). On the analysis day, the saliva samples were completely thawed, vortexed, and centrifuged at $1,500 \times \mathrm{g}$ (at $3,000 \mathrm{rpm}$ ) for 15 minutes according to the manual instructions.

We followed the EIA-Kit (Item No. 1-3002-5) instructions. The minimal detectable concentration was $0.003 \mu \mathrm{g} / \mathrm{dL}(0.08 \mathrm{nmol} / \mathrm{L})$. The intra-assay and inter-assay coefficient of variation was $3.35 \%$ and $3.75 \%$, respectively. The mean recovery was $100.8 \% \pm 3.7 \%$. The absorbance was 
analyzed using a Multiskan FC microplate photometer (Thermo Fisher Scientific, Vantaa, Finland) at $450 \mathrm{~nm}$. To estimate cortisol concentration from the measured sample absorbances, a standard curve was constructed using the known concentrations of cortisol. Furthermore, we calculated the percent bound (B/Bo) for each standard, control, and unknown by dividing the average optical density (OD) (B) by the average OD for the zero (Bo). If the cortisol value exceeded $3.0 \mu \mathrm{g} / \mathrm{dL}(82.77 \mathrm{nmol} / \mathrm{L})$, the sample was diluted with an assay diluent and rerun for accurate results. We assayed all samples in duplicate and used the average of the duplicates in the subsequent data analyses.

\section{Statistical analyses}

Statistical analyses were carried out with the SAS version 8 (SAS Institute Inc., Cary, NC, USA). The differences between the group averages and the cortisol data within each group were analyzed using an analysis of covariance (ANCOVA) for repeated measures with times, groups, and ages. All values were expressed as means \pm standard deviation, with a statistical significance level set at $\mathrm{p}<0.05$.

\section{RESULTS}

\section{Changes of cortisol concentration between horse groups}

The changes of cortisol concentration in the three groups according to the measured time are summarized in Table 1 and Figure 1. In a percentage relative to the base value, cortisol levels at Exercise 3 were confirmed to decrease in all groups as compared to the basal value percentage in the following sequence: $E R>T R>R R$. The highest peak was confirmed at Exercise 2 (ca. 131\%) of RR group and the lowest peak appeared in Exercise 3 (ca. 52\%) in ER group (Figure 1).

In the within-group comparison in the measured time, cortisol concentration levels in ER group significantly decreased by approximately $48 \%$ at Exercise $3(2.76 \pm 1.94$ $\mathrm{nmol} / \mathrm{L})$ as compared with the basal value $(5.31 \pm 3.82$

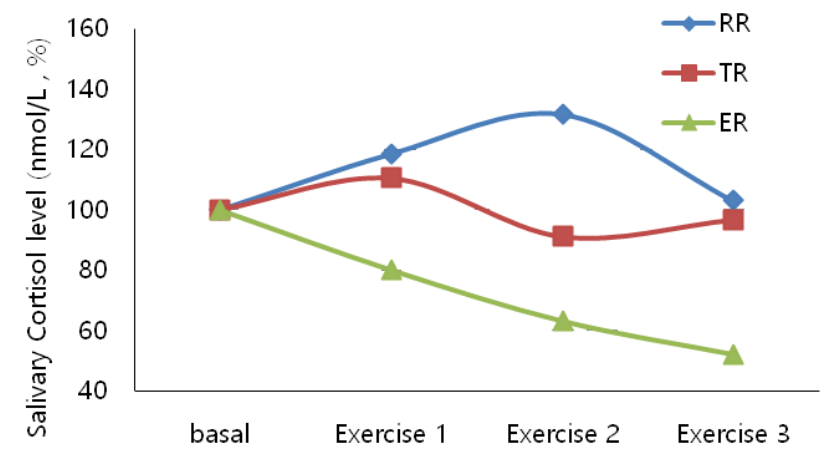

Figure 1. Rate of change of the salivary cortisol levels according to groups in horses.

$\mathrm{nmol} / \mathrm{L})(\mathrm{p}<0.01)$. However, cortisol concentration in $\mathrm{RR}$ and TR groups did not change significantly, ranging from the minimum value of $3.07 \pm 1.80 \mathrm{nmol} / \mathrm{L}$ to the maximum value of $4.01 \pm 2.51 \mathrm{nmol} / \mathrm{L}$ and the minimum value of $2.96 \pm 1.19 \mathrm{nmol} / \mathrm{L}$ to the maximum value of $2.44 \pm 1.16$ $\mathrm{nmol} / \mathrm{L}$, respectively.

In the comparison of the three groups in the measured time, salivary cortisol concentration at the basal values was significantly higher in ER group $(5.31 \pm 3.82 \mathrm{nmol} / \mathrm{L})$ than in TR group $(2.68 \pm 0.93 \mathrm{nmol} / \mathrm{L})$ and $R R$ group $(3.07 \pm 1.80$ $\mathrm{nmol} / \mathrm{L}) \quad(\mathrm{p}<0.05)$. Salivary cortisol concentration at Exercise 1 was remarkably higher in ER group (4.25 \pm 2.27 $\mathrm{nmol} / \mathrm{L})$ than in TR group $(2.96 \pm 1.19 \mathrm{nmol} / \mathrm{L})$ and $\mathrm{RR}$ $(3.61 \pm 1.42 \mathrm{nmol} / \mathrm{L})(\mathrm{p}<0.05)$. Salivary cortisol concentrations at Exercise 2 varied among the groups, with the value of $2.44 \pm 1.16 \mathrm{nmol} / \mathrm{L}$ in TR group, $4.01 \pm 2.51 \mathrm{nmol} / \mathrm{L}$ in $\mathrm{RR}$ group, and $3.35 \pm 2.27 \mathrm{nmol} / \mathrm{L}$ in ER group $(\mathrm{p}<0.05)$. No intergroup difference in salivary cortisol concentration at Exercise 3 was observed $(2.59 \pm 1.40 \mathrm{nmol} / \mathrm{L}$ in TR group, $3.14 \pm 1.78 \mathrm{nmol} / \mathrm{L}$ in $\mathrm{RR}$ group, and $2.76 \pm 1.94 \mathrm{nmol} / \mathrm{L}$ in ER group).

\section{Changes of cortisol concentration among horses from different age groups}

Age-specific changes of cortisol concentration according to the measured time are summarized in Table 2 and Figure 2. In a percentage relative to the basal value,

Table 1. Changes of cortisol concentration between groups of horses

\begin{tabular}{lcccc}
\hline Treatment $^{1}$ & \multicolumn{4}{c}{ Measurement time (Mean \pm SD) } \\
\cline { 2 - 4 } & Basal & Exercise 1 & Exercise 2 & Exercise 3 \\
\hline TR & $2.68^{\mathrm{B}, \mathrm{a}} \pm 0.93$ & $2.96^{\mathrm{B}, \mathrm{a}} \pm 1.19$ & $2.44^{\mathrm{B}, \mathrm{a}} \pm 1.16$ & $2.59^{\mathrm{A}, \mathrm{a}} \pm 1.40$ \\
RR & $3.07^{\mathrm{B}, \mathrm{a}} \pm 1.80$ & $3.61^{\mathrm{AB}, \mathrm{a}} \pm 1.42$ & $4.01^{\mathrm{A}, \mathrm{a}} \pm 2.51$ & $3.14^{\mathrm{A}, \mathrm{a}} \pm 1.78$ \\
ER & $5.31^{\mathrm{A}, \mathrm{a}} \pm 3.82$ & $4.25^{\mathrm{A}, \mathrm{ab}} \pm 2.27$ & $3.35^{\mathrm{AB}, \mathrm{b}} \pm 2.27$ & $\mathrm{NS}$ \\
Significance & $*$ & $*$ & $*$ & $2.76^{\mathrm{A}, \mathrm{b}} \pm 1.94$ \\
\hline
\end{tabular}

SD, standard deviation.

${ }^{1} \mathrm{TR}$, tourist riding group; RR, resting group; ER, education horse-riding group.

Levels of significance: NS, not significant; ${ }^{*} \mathrm{p}<0.05 ; * * \mathrm{p}<0.01$.

${ }^{a-b}$ Means with different superscripts in the same row significantly differ $(p<0.05)$.

${ }^{A-B}$ Means with different superscripts in the same column significantly differ $(p<0.05)$. 
Table 2. Changes of cortisol concentration between ages of horses

\begin{tabular}{lccccc}
\hline \multirow{2}{*}{ Treatment $^{1}$} & \multicolumn{5}{c}{ Measurement time $($ Mean \pm SD) } \\
\cline { 2 - 5 } & Basal & Exercise 1 & Exercise 2 & Exercise 3 \\
\hline A1 & $4.16^{\mathrm{A}, \mathrm{a}} \pm 2.57$ & $5.41^{\mathrm{A}, \mathrm{a}} \pm 3.33$ & $5.02^{\mathrm{A}, \mathrm{a}} \pm 3.50$ & $3.24^{\mathrm{A}, \mathrm{a}} \pm 3.33$ & $\mathrm{NS}$ \\
$\mathrm{A} 2$ & $3.34^{\mathrm{A}, \mathrm{a}} \pm 1.88$ & $3.55^{\mathrm{B}, \mathrm{a}} \pm 1.40$ & $3.40^{\mathrm{B}, \mathrm{a}} \pm 1.90$ & $2.96^{\mathrm{A}, \mathrm{a}} \pm 1.80$ & $\mathrm{NS}$ \\
$\mathrm{A} 3$ & $3.51^{\mathrm{A}, \mathrm{a}} \pm 1.88$ & $3.50^{\mathrm{B}, \mathrm{a}} \pm 1.21$ & $2.46^{\mathrm{B}, \mathrm{a}} \pm 0.91$ & $2.55^{\mathrm{A}, \mathrm{a}} \pm 0.94$ & $\mathrm{NS}$ \\
A4 & $4.64^{\mathrm{A}, \mathrm{a}} \pm 4.22$ & $3.06^{\mathrm{B}, \mathrm{ab}} \pm 1.51$ & $2.48^{\mathrm{B}, \mathrm{b}} \pm 1.64$ & $2.49^{\mathrm{A}, \mathrm{b}} \pm 0.86$ & $*$ \\
Significance & $\mathrm{NS}$ & $*$ & $*$ & $\mathrm{NS}$ & $*$ \\
\hline
\end{tabular}

SD, standard deviation.

${ }^{1} \mathrm{~A} 1,1$ to 5 years old; A2, 6 to 10 years old; A3, 11 to 15 years old; A4, 16 to 20 years old.

Levels of significance: NS, not significant; * $\mathrm{p}<0.05$.

${ }^{a-b}$ Means with different superscripts in the same row significantly differ $(\mathrm{p}<0.05)$.

A-B Means with different superscripts in the same column significantly differ $(\mathrm{p}<0.05)$.

cortisol levels at Exercise 3 were confirmed to decrease as compared to the basal value percentage in the following sequence: $\mathrm{A} 4>\mathrm{A} 3>\mathrm{A} 2>\mathrm{A} 1$ sequence. The highest peak was confirmed at Exercise 1 (ca. 130\%) of A1 group and the lowest peak appeared at Exercise 3 (ca. 54\%) of A4 group (Figure 1).

In the comparison by age according to the measured time, the average cortisol concentration ranged between $3.24 \pm 3.33 \mathrm{nmol} / \mathrm{L}$ and $5.41 \pm 3.33 \mathrm{nmol} / \mathrm{L}$ in $\mathrm{A} 1 ; 2.96 \pm 1.80$ $\mathrm{nmol} / \mathrm{L}$ and $3.55 \pm 1.40 \mathrm{nmol} / \mathrm{L}$ in $\mathrm{A} 2 ; 2.46 \pm 0.91 \mathrm{nmol} / \mathrm{L}$ and $3.51 \pm 1.88 \mathrm{nmol} / \mathrm{L}$ in $\mathrm{A} 3$, with no significant differences. However, cortisol concentration in A4 was $4.64 \pm 4.22$ $\mathrm{nmol} / \mathrm{L}$ at the basal value and considerably decreased (by ca. $98 \%$, to $2.49 \pm 0.86 \mathrm{nmol} / \mathrm{L})$ at Exercise $3(\mathrm{p}<0.05)$.

In the comparison by age groups of the measured time, no statistically significant differences were observed in cortisol concentration at basal values, ranging from $3.34 \pm 1.88 \mathrm{nmol} / \mathrm{L}$ to $4.64 \pm 4.22 \mathrm{nmol} / \mathrm{L}$. There was a significant difference in cortisol concentration at Exercise 1, ranging from $3.06 \pm 1.51 \mathrm{nmol} / \mathrm{L}$ to $5.41 \pm 3.33 \mathrm{nmol} / \mathrm{L}$ $(p<0.05)$. There was also a remarkable difference in cortisol concentration between horses from different age groups at Exercise 2, ranging from $2.48 \pm 1.64 \mathrm{nmol} / \mathrm{L}$ to $5.02 \pm 3.50$ $\mathrm{nmol} / \mathrm{L}(\mathrm{p}<0.05)$.

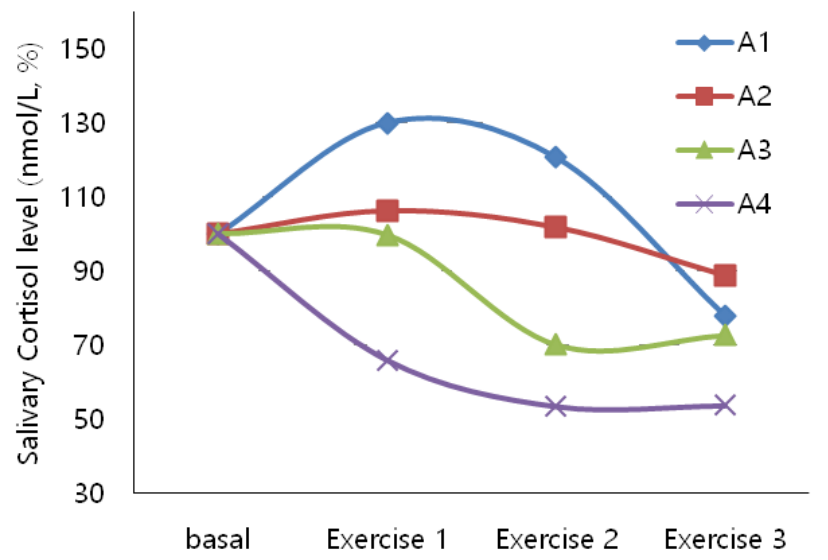

Figure 2. Rate of change of the salivary cortisol levels according to age in horses.

\section{DISCUSSION}

According to the analysis results of the three groups collected at 7:00 am, the average cortisol concentration at basal values was $3.81 \pm 2.86 \mathrm{nmol} / \mathrm{L}$. In a previous research on salivary cortisol concentration measured at roughly the same time, Peeters et al. $(2011 ; 2013)$ confirmed that cortisol concentration was 0.58 to $1.77 \mathrm{nmol} / \mathrm{L}$ at $\mathrm{n}=5$ and $\mathrm{n}=22$ with an average of $1.01 \pm 0.62 \mathrm{nmol} / \mathrm{L}$ and $1.19 \pm 0.54$ $\mathrm{nmol} / \mathrm{L}$, respectively. In addition, Moons et al. (2002) reported the average cortisol concentration of $2.77 \pm 0.45$ $\mathrm{nmol} / \mathrm{L}$ (Arabian horse; $\mathrm{n}=10$ ); this does not correspond with the results of the present study. However, since the type of work, environment, and sampling protocols in the present study differed from those used in Peeters et al. (2013), it is difficult to straightforwardly compare cortisol concentration in the two studies.

The animals in the present study were used in tourist riding experience and horse-riding education. The riders of the horses from TR group hold the iron in front of the saddle instead of reins. In this process, the horses for tourists were supposed to endure the hassle from the beginners' inappropriate posture and emotional yelling. Furthermore, they were required to have a monotonous daily life, going around a given course. Thus, we suggest that cortisol concentration in horses was high during the break due to the specificity of the schedule.

The meaningful finding of present study is that cortisol levels at Exercise 3 were confirmed to decrease in all groups as compared to the basal value percentage in the following sequence: $E R>T R>R R$. Also, the highest peak was confirmed at Exercise 2 (ca. 131\%) in RR group and the lowest peak appeared at Exercise 3 (ca. 52\%) in ER group (Figure 1). Said differently, stress levels increased in the non-exercise group (RR) as compared to the exercise groups.

Cortisol level percentage was always the highest in RR group at Exercise 1 (ca. 118\%), Exercise 2 (ca. 131\%), and Exercise 3 (ca. 102\%) and the lowest in ER group at Exercise 1 (ca. 80\%), Exercise 2 (ca. 63\%), and Exercise 3 
(ca. 52\%) during the exercise period. According to Strzelec et al. (2011), cortisol levels are affected by intensity and length.

In our study, for TR, i.e. the horse group used for tourist riding experience, there was no significant intergroup difference in the collected cortisol concentration. For RR, the collected cortisol concentration either increased or decreased with the passage of time; however, little intergroup difference was observed. Since TR group was the group used for horse riding experience, the horses in TR group exercised at a normal or fast speed. Furthermore, ER had a higher level of cortisol concentration at the basal value $(07: 00 \mathrm{~h})$ as compared to other groups. However, cortisol concentration in this study significantly decreased after exercising and remained at the similar level in other groups at Exercise 3. This coheres with Strzelec et al. (2011) who reported that cortisol concentration decreased more after than before dressage. In addition, the intensity and length of the exercise was performed in our study can be described that it does not affect the levels of cortisol of horses. As a result, we propose that stress can be reduced by moderate intensity and length of exercise.

The horses for riding can be easily affected by the riding level of the rider. In order to be a professional rider, an aid, i.e. a form of communication between a horse and a rider, should be matched (Kang et al., 2010). A horse can allow a rider on its back with ease when the aids between a horse and a rider work well. Thus, we assume that the moderate level of walk and trot during riding lessons, not a fast speed with riders who constantly practice riding, caused a decrease in cortisol concentration.

Another significant finding of the present study is that cortisol levels in Exercise 3 were confirmed to decrease as compared to the basal value percentage in the following sequence: $\mathrm{A} 4>\mathrm{A} 3>\mathrm{A} 2>\mathrm{A} 1$. The highest peak was confirmed at Exercise 1 (ca. 130\%) of the A1 group and the lowest peak appeared in Exercise 3 (ca. 54\%) of the A4 group (Figure 2). This is an interesting result. The lowest peak of cortisol level at Exercises 1, 2, and 3 showed a low level of cortisol in the older group, while the highest level was observed in the younger group. This suggests that an older age did not affect the stress level.

In the age-specific comparison of cortisol concentration over time, no intergroup differences at the basal values were observed; however, Exercise 1 was different (Table 2 and Figure 2). Cortisol concentration at the basal value and Exercise 1 increased from $4.16 \pm 2.57 \mathrm{nmol} / \mathrm{L}$ to $5.41 \pm 3.33$ $\mathrm{nmol} / \mathrm{L}$ in the youngest group (A1), marking the highest value; meanwhile, it decreased from $4.64 \pm 4.22 \mathrm{nmol} / \mathrm{L}$ to $3.06 \pm 1.51 \mathrm{nmol} / \mathrm{L}$ in the oldest group (A4), marking the lowest value. In addition, our results suggest that cortisol concentration gets lower as the age increases. In the comparison of each age group according to the measured period, our results demonstratethat the concentration highly decreased in A4 $(\mathrm{p}<0.05)$. According to Nogueira and Barnabe (1997) analysis of cortisol concentration by age of racehorses, the oldest group had the lowest cortisol concentration. This result can be considered to reflect the ability of horses to adapt through experience.

In conclusion, salivary cortisol levels were lower in the exercise groups than in the non-exercise group. Also, the effects of cortisol levels according to horses' age were confirmed to decrease in the following order: A4, A3, A2, and A1. Also, cortisol levels of all groups at Exercise 3 were lower than before basal. In other words, exercise intensity and length did not affect the actual stress of the horses. Therefore, resting without any particular exercise can also increase the stress level in horses. It is better to exercise, since exercise can reduce stress level as compared with non-exercise, even in cases when riders are clumsy riders or lack relevant horse-riding experience.

This study has several limitations. First, the sample with which we investigated the changes in the cortisol concentration level according to age of horses was limited, which makes it difficult to e accurately assess. Second, the resting environment was not fully considered, because RR group was tied with a rope and did not graze in the pasture during rest. A more accurate estimate can be made if these limitations are addressed in further research. Despite the limitations, the results of the present study contribute to obtaining basal values and provide a meaningful insight for equestrian center owners and educational riding instructors into a better horse management.

\section{IMPLICATIONS}

In the present study, stress levels in horses involved in different types of work were confirmed by measuring salivary cortisol concentration. Cortisol levels showed a higher level in the non-exercise group than the exercise groups. In comparison with age, cortisol levels were the lowest in the oldest group of horses. Therefore, the differences in exercise intensity, such as those between walking, trotting, and light canter, did not affect the actual stress of the horses.

\section{CONFLICT OF INTEREST}

We certify that there is no conflict of interest with any financial organization regarding the material discussed in the manuscript.

\section{ACKNOWLEDGMENTS}

This work was supported by a grant from (No. PJ010224022014) Rural Development Administration, Republic of Korea and also this study was partially supported by the Horse Resources Research Institute. The 
authors are pleased to thank the members of the Song Dang farm and Jeju Horse Land, Jeju, South Korea. We also thank graduate students who helped the measurement and analysis at the Clinical Pathology Laboratory, College of Veterinary Medicine, Jeju National University.

\section{REFERENCES}

Ferlazzo, A., P. Medica, C. Cravana, and E. Fazio. 2009. Endocrine changes after experimental showjumping. Comp. Exerc. Phys. 6:59-66.

Harewood, E. I. and C. M. McGowan. 2005. Behavioral and physiological responses to stabling in Naive Horses. J. Equine Vet. Sci. 4:164-170.

Kang, O. D., Y. C. Ryu, C. C. Ryew, W. Y. Oh, C. E. Lee, and M. S. Kang. 2010. Comparative analyses of rider position according to skill levels during walk and trot in Jeju horse. Hum. Mov. Sci. 29:956-963.

Kędzierski, W., K. Strzelec, A. Cywinska, and S. Kowalik. 2013. Salivary cortisol concentration in exercised thoroughbred horses. J. Equine Vet. Sci. 33:1106-1109.

Larsson, L., P. H. Pilborg, M. Jonansen, M. T. Christophersen, A. Holte, L. Roepstorff, L. H. Olsen, and A. P. Harrison. 2013. Physiological parameters of endurance horses pre compared basal values post-race, correlated with performance: A two race study from Scandinavia. ISRN Vet. Sci. Article, ID 684353: 12pages.

Linden, A., T. Art, H. Amory, D. Desmecht, and P. Lekeux. 1991. Effect of 5 different types of exercise, transportation and ACTH administration of plasma cortisol concentration in sport horses. Equine Exerc. Physiol. 3:391-396.

Malinowski, K., E. J. Shock, P. Rochelle, C. F. Kearns, P. D. Guirnalda, and K. H. McKeever. 2006. Plasma beta-endorphin, cortisol and immune responses to acute exercise are altered by age and exercise training in horses. Equine Vet. J. (Suppl.) 36: 267-273.

Marc, M., N. Parvizi, F. Ellendorff, E. Kallweit, and F. Elsaesser. 2000. Plasma cortisol and ACTH concentrations in the warmblood horse in response to a standardized treadmill exercise test as physiological markers for evaluation of training status. J. Anim. Sci. 78:1936-1946.
Moons, C., C. R. Heleski, C. M. Leece, and A. J. Zanella. 2002. Conflicting results in the association between plasma and salivary cortisol level in foals. Proceedings of the Dorothy Russel Havemeyer Foundation Workshop "Horse Behavior and Welfare". Holar College te Holar, Iceland.

Mostl, E. and R. Palme. 2002. Hormones as indicators of stress. Domest. Anim. Endocrinol. 23:67-74.

Nogueira, G. P. and R. C. Barnabe. 1997. Is the Thoroughbred race-horse under chronic stress? Brazilian J. Med. Biol. Res. 30:1237-1239.

Peeters, M., C. Coline, J-F. Becker, D. Ledoux, and M. Vandenheede. 2011. Comparison between blood serum and salivary cortisol concentrations in horses using an adrenocorticotropic hormone challenge. Equine Vet. J. 43:487493.

Peeters, M. M., C. C. Coline, J-F. Becker, and M. Vandenheede. 2013. Rider and horse salivary cortisol levels during competition and impact on performance. J. Equine. Vet. Sci. 33:155-160.

Shanahan, S. 2003. Trailer loading stress in horses: Behavioral and physiological effects of nonaversive training (TTEAM). J. Appl. Anim. Welf. Sci. 6:263-274.

Strzelec, K., M. Kankofer, and S. Pietrzak. 2011. Cortisol concentration in the saliva of horses subjected to different kinds of exercise. Acta Vet. Brno 80:101-105.

Strzelec, K., W. Kedzierski, A. Bereznowski, I. Janczarek, K. Bocian, and M. Racosz. 2013. Salivary cortisol Levels in horses and their riders during Three-day-events. Bull. Vet. Inst. Pulawy 57:237-241.

Van Der Kolk, J. H., R. F. Nachreiner, H. C. Scott, K. R. Refsal, and K. J. Zanella. 2001. Salivary and plasma concentration of cortisol in normal horses and horses with Cushing's disease. Equine Vet. J. 33:211-213.

Vincze, A., C. S. Szabó, Á. Heves, S. Veres, D. Ütő, and L. Babinszky. 2010. Effect of age and event on post exercise values of blood biochemical parameters in show jumping horses. Acta Agraria Kaposváriensis 14:185-191.

Wellhoener, P., J. Born, H. L. Fehm, and C. Dodt. 2004. Elevated resting and exercise-induced cortisol levels after mineralocorticoid receptor blockade with canrenoate in healthy humans. J. Clin. Endocrinol. Metab. 89:5048-5052. 